\title{
Changes in penicillinase-producing Neisseria gonorrhoeae isolated in London
}

\author{
C. A. ISON and C. S. F. EASMON \\ Department of Medical Microbiology, St Mary's Hospital Medical School, Paddington, London W2 1PG
}

\begin{abstract}
Summary. To investigate changes in the gonococcal population over time, the plasmid content, serotype and auxotype have been determined for strains of penicillinaseproducing Neisseria gonorrhoeae (PPNG) isolated from patients attending the Praed Street Clinic for Sexually Transmitted Diseases between 1978 and 1987. Three distinct changes have been identified: (i) in the main plasmid type, from PPNG with the 3.2-Mda plasmid before 1982 to strains with the 4.4-Mda plasmid between 1982 and 1985; (ii) the decline during this time of strains also carrying the $24 \cdot 5-\mathrm{Mda}$ conjugal plasmid; (iii) the re-emergence of PPNG with the 3.2-Mda plasmid in 1986. The three typing methods used have identified eight clusters of strains which have been prevalent in different years between 1978 and 1987.
\end{abstract}

\section{Introduction}

Penicillinase-producing Neisseria gonorrhoeae (PPNG) was first isolated in England in $1976^{1,2}$ and simultaneously in the USA. ${ }^{3,4}$ The TEM-1 type $\beta$-lactamase was found to be encoded on plasmids of either $3.2 \mathrm{Mda}$ or $4.4 \mathrm{Mda}$ which had arisen in Africa and Asia respectively. ${ }^{5}$ More recently, penicillinase-encoding plasmids of 2.9 Mda, 3.05 Mda and 4.1 $\mathrm{Mda}^{6-8}$ have also been reported in $N$. gonorrhoeae. A conjugal plasmid of $24.5 \mathrm{Mda}$ is carried by some strains and is necessary for mobilisation of the penicillinase plasmids during conjugation into other gonococcal strains. ${ }^{9}$

In England and Wales the number of strains of PPNG reported rose exponentially to a total of 1223 in $1982 .{ }^{10}$ In 1983 there was a further smaller increase to 1227 strains followed by a steady decline. Unconfirmed figures for 1987 show only 235 reported PPNG strains. At St Mary's Hospital a similar pattern has been seen with an increase until 1983 to 277 strains of PPNG. ${ }^{11}$ The number of PPNG isolated has since fallen to $192,95,112$ and 52 in 1984, 1985, 1986 and 1987 respectively. However, PPNG have continued to represent approximately $5 \%$ of total isolates due to the dramatic fall in the total number of gonococcal infections.

Strains of PPNG can be distinguished by their plasmid type and auxotype and we have previously reported our experience with PPNG isolated at St Mary's Hospital between 1978 and 1984. ${ }^{11}$ Any

Received 6 March 1989; accepted 18 May 1989. further discrimination has been hampered by the lack of a suitable method for epidemiological study. However, in 1984 a serological classification of $N$. gonorrhoeae was described ${ }^{12}$ based on a panel of monoclonal antibodies raised to epitopes of the major outer membrane protein, $\mathrm{PI} .{ }^{13} \mathrm{We}$ have used this typing scheme, in addition to plasmid content and auxotyping, to give enhanced discrimination and so to determine changes in strains of PPNG isolated between 1978 and 1987.

\section{Materials and methods}

\section{Bacteria}

A total of 1037 strains of PPNG was isolated from patients attending the Praed Street Clinic for Sexually Transmitted Diseases between 1978 and 1987. All strains were isolated and identified as described previously ${ }^{11}$ and stored in glycerol $15 \% \mathrm{v} / \mathrm{v}$ broth in liquid nitrogen. It was not always possible to either store every strain of PPNG isolated or to retrieve every strain stored. In this study the plasmid analysis and auxotyping 'were performed at intervals over the years. The serotyping was performed recently; therefore, the strains were subcultured for a second time from our collection. At least $75 \%$ of strains isolated from each year were available for testing except for strains from 1982 and 1985 of which, due to problems with storage, $45 \%$ and $61 \%$ were tested respectively.

\section{Plasmid content}

Strains of PPNG were grown overnight on GC Agar Base (Difco) supplemented with IsoVitaleX $1 \%$ and 
harvested in saline. The plasmids were extracted by the rapid method of Birnboim and Doly ${ }^{14}$ and electrophoresed on agarose $1 \%$ gels in $20 \mathrm{mM}$ sodium acetate buffer, $\mathrm{pH} 7 \cdot 8$, and visualised by staining with ethidium bromide.

\section{Serotyping}

Twelve monoclonal antibodies (Syva USA, Palo Alto) were coated on to a $10 \%$ suspension of staphylococcal Protein A (Calbiochem, Cambridge Bioscience), washed in $0.15 \mathrm{M}$ phosphate-buffered saline (PBS) and resuspended to a $1 \%$ suspension. All strains of PPNG were grown at $36^{\circ} \mathrm{C}$ for $18 \mathrm{~h}$ in $\mathrm{CO}_{2} 7 \%$ in air. A cloudy suspension was made in PBS and boiled for $10 \mathrm{~min}$ to expose the PI epitopes. One drop of each reagent was mixed with one drop of bacterial suspension on a glass slide and rotated for exactly $2 \mathrm{~min}$. The results were read macroscopically and scored by degree of agglutination from very strongly $(4+)$ to weakly reactive $(1+)$. Any reaction of more than $1+$ was considered positive and a serovar was assigned according to the nomenclature of Knapp et al. ${ }^{12}$ Strains belonging to serovars IA-1 and IA-2 $2^{12}$ together with serovars IB-5 and IB- $7^{15}$ differ only by a single reaction and have been shown previously, and in this study, to have similar profiles. Each pair has been considered as one serovar.

\section{Auxotyping}

Strains of PPNG were auxotyped either by the method of Catlin et al. ${ }^{16}$ or by the modification of Copley and Egglestone ${ }^{17}$ An overnight growth of each organism was suspended in saline and $1-\mu l$ volumes were inoculated on to a range of chemically defined media by means of a multipoint inoculator (Denley). After incubation at $36^{\circ} \mathrm{C}$ in $\mathrm{CO}_{2} 7 \%$ in air for $24 \mathrm{~h}$, the plates were examined for the presence of macrocolonies. Media lacking proline, arginine, hypoxanthine, uracil, histidine and methionine were used in addition to a complete medium. Strains requiring arginine were tested for their ability to utilise ornithine as an alternative substrate.

\section{Statistical analysis}

The data were analysed by the Statistical Package for
Social Sciences (SPSS). Differences between the number of strains in certain serovars with either the 3.2- or 4.4Mda plasmid were determined by the $\chi^{2}$ test.

\section{Results}

The plasmid content of 726 strains of PPNG was determined. Before 1982, 39 (52\%) of the 75 strains tested carried the 3.2-Mda penicillinase-encoding plasmid of which only $9(23 \%)$ also carried the $24.5-$ Mda conjugal plasmid. Between 1982 and 1985, the percentage of strains tested that carried the $3 \cdot 2$ Mda plasmid fell from $30 \%$ (29 of 96 ) to $19 \%$ (11 of 58 ), of which less than $5 \%$ in each year also carried the 24-5-Mda plasmid (table I).

In $1982,70 \%$ of PPNG tested carried the $4.4-$ Mda plasmid, the majority of which, $44(66 \%)$ of 67 , also carried the conjugal plasmid. These strains continued to increase in proportion, reaching $81 \%$ (124 of 157 strains tested) in 1984, although between 1983 and 1985 the number of strains carrying both the 4.4- and 24.5-Mda plasmids slowly declined (table I). In 1985 , only $23 \%$ (11 of 47 ) of such strains carried the $24 \cdot 5$-Mda plasmid.

In contrast, during 1986 the pattern of plasmids isolated changed. There was an increase to $61 \%(55$ of 90 ) in strains carrying the $3 \cdot 2-\mathrm{Mda}$ plasmid of which $40 \%$ (22 of 55 ) also carried the $24 \cdot 5-\mathrm{Mda}$ plasmid. There was an overall decrease in strains carrying the $4 \cdot 4-\mathrm{Mda}$ plasmid and the number additionally carrying the $24 \cdot 5-\mathrm{Mda}$ plasmid continued to fall (table I).

In 1987 , the pattern of strains carrying the $3 \cdot 2-$ Mda plasmid remained as in 1986, but of the 17 strains carrying the $4 \cdot 4-\mathrm{Mda}$ plasmid, $14(82 \%)$ were now carrying the $24 \cdot 5$-Mda plasmid also. However, changes seen at this time should be interpreted with caution because considerably fewer strains of PPNG were being isolated than in previous years.

Of the 726 PPNG tested for plasmids, the source of the infecting strain was known for only 358 . The distribution of plasmid type with the main geo-

Table I. Distribution of plasmid types among PPNG isolated between 1982 and 1987 (missing strains in each year were $116,65,35,37,22,14$ respectively)

\begin{tabular}{l|cccccc}
\hline & \multicolumn{5}{|c}{ Number $(\%)$ of strains isolated in } \\
$\begin{array}{l}\text { Plasmid } \\
\text { type (Mda) }\end{array}$ & 1982 & 1983 & 1984 & 1985 & 1986 & 1987 \\
\cline { 2 - 7 } & & & & & \\
$3 \cdot 2$ & $26(27)$ & $46(22)$ & $27(17)$ & $10(17)$ & $33(37)$ & $12(31)$ \\
$3 \cdot 2+24 \cdot 5$ & $3(3)$ & $11(5)$ & $6(4)$ & $1(2)$ & $22(24)$ & $9(24)$ \\
$4 \cdot 4$ & $23(24)$ & $97(46)$ & $104(66)$ & $36(62)$ & $26(29)$ & $3(8)$ \\
$4 \cdot 4+24 \cdot 5$ & $44(46)$ & $58(27)$ & $20(13)$ & $11(19)$ & $9(10)$ & $14(37)$ \\
\hline
\end{tabular}


graphical areas seen is shown in table II. Most PPNG isolated from infections acquired in the Far East carried the 4.4-Mda plasmid (32 of 35, 91\%). Of the strains from infections contracted in Africa, $34(62 \%)$ of 55 also carried the $4 \cdot 4-\mathrm{Mda}$ plasmid, with only $21(38 \%)$ of 55 carrying the "African type" 3.2-Mda plasmid. The strains acquired in Britain had a plasmid pattern similar to that of strains contracted in Africa (table II).

A total of 634 strains was available for serotyping and auxotyping. Twenty-three serovars were identified, eight IA and 15 IB (table III). Four serovarsIA- $1 / 2$, IA-6, IB-1 and IB-5/7-accounted for $75 \%$

Table II. Association of plasmid type and source of PPNG infection

\begin{tabular}{|c|c|c|c|}
\hline \multirow{2}{*}{$\begin{array}{l}\text { Plasmid } \\
\text { (Mda) }\end{array}$} & \multicolumn{3}{|c|}{$\begin{array}{c}\text { Number }(\%) \text { of strains from infections } \\
\text { acquired in }\end{array}$} \\
\hline & Far East & Africa & UK \\
\hline $\begin{array}{l}3 \cdot 2 \\
3 \cdot 2+24 \cdot 5 \\
4 \cdot 4 \\
4 \cdot 4+24 \cdot 5\end{array}$ & $\begin{array}{c}1(3) \\
2(6) \\
17(48) \\
15(43)\end{array}$ & $\begin{array}{c}17(31) \\
4(7) \\
18(32) \\
16(28)\end{array}$ & $\begin{array}{r}78(28) \\
27(10) \\
105(38) \\
58(22)\end{array}$ \\
\hline
\end{tabular}

(476 of 634) of the total number tested. Four of the seven auxotypes found accounted for $603(95 \%)$ of the 634 strains of PPNG. Of the 634 strains, 206 $(32 \%)$ were prototrophic, $331(52 \%)$ required proline and $31(5 \%)$ required arginine; $35(6 \%)$ required proline and arginine. The distribution of the four main auxotypes in each serovar is shown in table III. In serovar IA-1/2, the strains were almost equally divided between prototrophic, proline- or arginine-requiring and in serovar IB-5/7 between prototrophic and proline-requiring. In contrast, serovars IA-6, IA-10, IB-1 and IB-3 were mainly proline-requiring and IA-4 was prototrophic (table III).

A total of 615 strains of PPNG was tested for both serovar and plasmid content. Certain serovars were found amongst strains of PPNG carrying either the 4.4-Mda or 3.2-Mda penicillinase plasmid (table IV); 81\% (333 of 409) of strains with the 4.4Mda plasmid belonged to serovars IA-6, IB-1 and IB-5/7, in comparison to $35 \%$ (73 of 206 ) of strains carrying the $3 \cdot 2-$ Mda plasmid $(\mathrm{p}=<0.001)$ (table IV). In contrast, $55 \%$ (112 of 206$)$ of strains with the $3 \cdot 2-\mathrm{Mda}$ plasmid belonged to serovars IA- $1 / 2$, IA-4, IA-10 and IB-12 compared to only $7 \%$ (29 of 409 ) of strains with the $4 \cdot 4-\mathrm{Mda}$ plasmid $(\mathrm{p}=<0.02)$.

Table III. Distribution of serovars and auxotypes of 634 strains of PPNG

\begin{tabular}{|c|c|c|c|c|c|c|}
\hline \multirow[b]{2}{*}{ Serovar } & \multirow{2}{*}{$\begin{array}{c}\text { Number }(\%) \\
\text { of strains }\end{array}$} & \multicolumn{5}{|c|}{ Number of strains of auxotype } \\
\hline & & proto & pro & $\arg$ & $\mathrm{pa}$ & others \\
\hline IA- $1 / 2$ & $73(11 \cdot 5)$ & 22 & 21 & 18 & 3 & 9 \\
\hline IA-3 & $3(0 \cdot 5)$ & 2 & 1 & 0 & 0 & 0 \\
\hline IA-4 & $31 \quad(4.9)$ & 22 & 5 & 1 & 0 & 3 \\
\hline IA-5 & $3(0.5)$ & 3 & 0 & 0 & 0 & 0 \\
\hline IA-6 & $103(16 \cdot 2)$ & 23 & 72 & 2 & 3 & 3 \\
\hline IA-8 & $2(0 \cdot 3)$ & 2 & 0 & 0 & 0 & 0 \\
\hline IA-10 & $26(4 \cdot 1)$ & 3 & 17 & 4 & 2 & 0 \\
\hline IA-16 & $2(0 \cdot 3)$ & 2 & 0 & 0 & 0 & 0 \\
\hline IB-1 & $137(21 \cdot 6)$ & 31 & 89 & 0 & 10 & 7 \\
\hline IB-2 & $15(2 \cdot 4)$ & 5 & 10 & 0 & 0 & 0 \\
\hline IB-3 & $26(4 \cdot 1)$ & 3 & 16 & 5 & 2 & 0 \\
\hline IB-4 & $3(0.5)$ & 2 & 1 & 0 & 0 & 0 \\
\hline IB-5/7 & $180(28 \cdot 3)$ & 74 & 88 & 0 & 12 & 2 \\
\hline IB-8 & $3(0 \cdot 5)$ & 1 & 0 & 1 & 0 & 1 \\
\hline IB-9 & $1(0 \cdot 16)$ & 1 & 0 & 0 & 0 & 0 \\
\hline IB-12 & $14(2 \cdot 2)$ & 6 & 4 & 0 & 3 & 1 \\
\hline IB-18 & $1(0 \cdot 16)$ & 0 & 1 & 0 & 0 & 0 \\
\hline IB-19 & $1(0 \cdot 16)$ & 1 & 0 & 0 & 0 & 0 \\
\hline IB-20 & $1(0 \cdot 16)$ & 0 & 0 & 0 & 0 & 0 \\
\hline IB-22 & $1(0 \cdot 16)$ & 1 & 0 & 0 & 0 & 0 \\
\hline IB-26 & $3(0.5)$ & 1 & 2 & 0 & 0 & 0 \\
\hline IB-30 & $1(0 \cdot 16)$ & 1 & 0 & 0 & 0 & 0 \\
\hline IB-31 & $4(0.64)$ & 0 & 4 & 0 & 0 & 0 \\
\hline
\end{tabular}


Table IV. Distribution of serovars in strains of PPNG carrying the $4 \cdot 4$ - or 3.2-Mda plasmid

\begin{tabular}{|c|c|c|c|c|}
\hline \multirow{3}{*}{$\begin{array}{l}\text { Serovar } \\
\text { IA } 1 / 2\end{array}$} & \multicolumn{4}{|c|}{$\begin{array}{c}\text { Number }(\%) \text { of strains with plas- } \\
\text { mid type }\end{array}$} \\
\hline & \multicolumn{2}{|c|}{$\begin{array}{l}4 \cdot 4 \mathrm{Mda} \\
\quad(409)\end{array}$} & \multicolumn{2}{|c|}{$\begin{array}{l}3 \cdot 2 \mathrm{Mda} \\
(206)\end{array}$} \\
\hline & 14 & $(3.4)$ & 58 & $(28 \cdot 1)$ \\
\hline IA -4 & 5 & $(1 \cdot 2)$ & 26 & $(12.6)$ \\
\hline IA-6 & 84 & $(20 \cdot 5)$ & 16 & $(7 \cdot 8)$ \\
\hline $\mathrm{IA}-10$ & 5 & $(1 \cdot 2)$ & 19 & $(9 \cdot 2)$ \\
\hline IB-1 & 105 & $(25 \cdot 6)$ & 27 & $(13 \cdot 2)$ \\
\hline IB-2 & 11 & $(2 \cdot 7)$ & 4 & $(2 \cdot 0)$ \\
\hline IB-3 & 19 & $(4 \cdot 7)$ & 7 & $(3 \cdot 4)$ \\
\hline IB-5/7 & 144 & $(35 \cdot 2)$ & 30 & $(14 \cdot 6)$ \\
\hline IB-12 & 5 & $(1 \cdot 2)$ & 9 & $(4 \cdot 4)$ \\
\hline Others & 17 & $(4 \cdot 7)$ & 9 & $(4 \cdot 8)$ \\
\hline
\end{tabular}

A total of 61 auxotype/serovar (A/S) classes was found of which eight accounted for $44 \%$ (281 of 634) of the population tested. When these eight A/S classes were divided by plasmid content their frequency was found to vary from year to year (table V). For example, a cluster of pro/IA-6 strains with the 4.4-Mda plasmid was found in 1984 and two clusters of strains of proto/IB-1 and pro,arg/ IB- 1 , both with the $3 \cdot 2-\mathrm{Mda}$ plasmid, were found in 1986.

In our experience PPNG were rarely isolated from male homosexuals (22 out of 1037). Seventeen of these strains were available for testing and belonged to serovars IA-4 (4 strains), IA-6 (5), IB-1 (2), IB-4 (1), IB-5/7 (4) and IB-12 (1).

\section{Discussion}

The Praed Street Clinic for Sexually Transmitted Diseases is a large open access clinic in the centre of a cosmopolitan city. Many of the patients attending this clinic are transient, either in London or England, and the remainder are drawn from a large area in and around London. Therefore, it is surprising that the population of strains of PPNG tested in this study was relatively homogeneous23 serovars and $61 \mathrm{~A} / \mathrm{S}$ classes were found. This contrasts with the 45 serovars and $117 \mathrm{~A} / \mathrm{S}$ classes found amongst a similar number of strains of nonPPNG tested from patients attending the same clinic between 1984 and $1987^{15}$ and suggests limitation of PPNG within the general gonococcal population.

Over the past 9 years there have been major changes in the types of PPNG isolated at St Mary's Hospital. As it was impossible to test every strain isolated, these changes must be interpreted with caution. Distinct clusters of similar strains have occurred. Unfortunately, with our varied and mobile patient population, it is likely that we have seen only part of the epidemiological pattern represented by these clusters. The main changes in PPNG can be summarised as follows: firstly the emergence of strains with the 4.4-Mda plasmid as the predominant PPNG type from 1982 to 1985 ; secondly, the steady loss of carriage of the conjugal plasmid in these strains; and thirdly, the reemergence of strains with the $3 \cdot 2-\mathrm{Mda}$ plasmid in 1986.

These specific changes have been set against a background of steadily decreasing numbers of all

Table V. The distribution of the predominant A/S classes in the PPNG population tested between 1982 and 1987

\begin{tabular}{lc|rrrrrr}
\hline & & \multicolumn{6}{|c}{ Number of strains isolated in } \\
\cline { 3 - 8 } A/S class & Total & 1982 & 1983 & 1984 & 1985 & 1986 & 1987 \\
\hline $4 \cdot 4 M d a$ & & & & & & & \\
pro/IA-6 & 66 & 3 & 1 & 39 & 6 & 8 & 2 \\
pro/IB-1 & 81 & 15 & 17 & 25 & 12 & 7 & 3 \\
pro/IB-5/7 & 81 & 13 & 46 & 17 & 0 & 3 & 1 \\
proto/IB-5/7 & 59 & 17 & 19 & 8 & 2 & 4 & 3 \\
3.2 Mda & & & & & & & \\
arg/IA-2 & 17 & 7 & 8 & 0 & 0 & 0 & 0 \\
proto/IA-4 & 17 & 1 & 8 & 3 & 0 & 1 & 0 \\
proto/IB-1 & 11 & 1 & 0 & 1 & 0 & 8 & 0 \\
pro, arg/IB-1 & 9 & 0 & 0 & 0 & 0 & 7 & 0 \\
\hline
\end{tabular}

pro $=$ Proline requiring $;$ arg $=$ arginine requiring $;$ proto $=$ non requiring .

* Includes strains isolated between 1978 and 1981. 
gonococcal isolates including PPNG since 1984, although the rate of infection with PPNG does not seem to have changed significantly. One effect of this fall in total numbers of PPNG is that the occurrence of a cluster of similar strains has a much larger effect on the overall pattern of observed PPNG infection.

The change from a predominance of strains carrying the $3 \cdot 2-\mathrm{Mda}$ plasmid to strains carrying the 4.4-Mda plasmid also occurred in Florida between 1983 and $1984^{18}$ and in Amsterdam in 1982. ${ }^{19}$ Strains carrying the $4 \cdot 4$-Mda plasmid have been shown by several groups to be more resistant to a range of antimicrobial agents than strains carrying the $3 \cdot 2-\mathrm{Mda}$ plasmid ${ }^{5,11,18,20}$ and this could confer a selective advantage. It is difficult to explain the decrease in the number of PPNG with both the 4.4-Mda plasmid and the $24 \cdot 5-\mathrm{Mda}$ conjugal plasmid. The latter plasmid is necessary for transfer of the penicillinase plasmid between strains of $N$. gonorrhoeae; hence its decline suggests that infections between 1983 and 1985 were caused by transmission of a penicillinase-producing strain rather than movement of the plasmid into other gonococcal strains.

Strains of PPNG with the 3-2-Mda plasmid did not emerge in greater numbers in London until 1986. Many of these strains also carried the conjugal plasmid which previously had been seen only occasionally in our PPNG population. An outbreak of these strains occurred in Amsterdam ${ }^{21}$ in 1981 but either the strains never spread to London or failed to become established.

Although we have seen these three dramatic changes in the PPNG population in London since 1978 , the factors that decide or influence these changes are not understood. It could be attributed to importation of strains either from abroad or outside the local area. An alternative possibility is that the penicillinase-encoding plasmids have been transferred into indigenous strains and it is this population that determines the prevalence. However, the distribution of serovars differs significantly between our PPNG and non-PPNG populations. The predominant serovars in strains of non-PPNG, which would act as recipients of the penicillinase encoding plasmids, are IA-1/2, IB-1, IB- 2 and

\section{REFERENCES}

1. Phillips I. $\beta$-lactamase-producing, penicillin-resistant gonococcus. Lancet 1976; 2:656-657.

2. Percival A, Rowlands J, Corkhill J E et al. Penicillinaseproducing gonococci in Liverpool. Lancet 1976; 2: 1379-1382.
IB- $3^{15}$, of which only IA- $1 / 2$ and IB- 1 are found in the PPNG population. This could be due to differences in the ability of strains to accept the penicillinase plasmids but our own studies have shown that, if this is true, it is not determined by the serovar (Gill, Woodford and Ison, unpublished data).

The plasmid profiles of the strains of PPNG that have been acquired in England were similar to those of African strains probably; this reflects the large number of Nigerian patients attending our clinic. It is surprising that strains known to have originated in Africa carry both the $3 \cdot 2-\mathrm{Mda}$ plasmid, once typical of African strains, and also the 4.4-Mda plasmid, originally associated with Asian strains. In contrast, strains known to have been acquired in the Far East have retained the typical 4.4-Mda plasmid. The spread of the 3.2Mda plasmid into Asian strains has probably been restricted by the lack of the conjugal plasmid in most strains.

It is very difficult at this time to compare strains of PPNG from different sources because there are few studies in which either auxotyping or the same panel of antibodies for serotyping have been used. There is some evidence that predominant strains were of similar A/S classes in London and Florida, e.g., serovar pro/IA-6 was common in strains carrying the 4.4-Mda plasmid in 1984 in both populations. However, the increase in strains carrying the 3.2-Mda plasmid in Florida in 1986 was due to strains of pro/IB-2 and pro/IA-1/2, whereas in London strains of serovar IB-1 accompanied this increase. Bygdeman ${ }^{22}$ has shown that proto/IA-6 strains are predominantly from Asia whereas strains of pro/IA-6, which were prevalent in 1984 in our study, are found in Africa, Asia and Europe. Strains belonging to A/S class proto/IA-4 were also shown to have been imported from Africa into Europe and have been found in our population and in those from the Netherlands. ${ }^{19}$ It is hoped that with the wide availability of a standard panel of monoclonal antibodies for serotyping $N$. gonorrhoeae it will be possible to monitor the future movement of strains of PPNG.

We thank Syva Co., Palo Alto for the gift of the monoclonal antibodies.

3. Centers for Disease Control. Penicillinase-producing Neisseria gonorrhoeae. Morbidity and Mortality Weekly Report 1976; $25: 261$.

4. Ashford W A, Golash R G, Hemming V G. Penicillinaseproducing Neisseria gonorrhoeae. Lancet 1976; 2 : 657658.

5. Perine P L, Thornsberry C, Schalla W et al. Evidence for 
two distinct types of penicillinase-producing Neisseria gonorrhoeae. Lancet 1977; 2: 993-995.

6. van Embden J D A, Dessens-Kroon M, van Klingeren B. A new $\beta$-lactamase plasmid in Neisseria gonorrhoeae. $J$ Antimicrob Chemother 1985; 15: 247-250.

7. Yeung K-H, Dillon J R, Pauze M, Wallace E. A novel 4.9kilobase plasmid associated with an outbreak of penicillinase-producing Neisseria gonorrhoeae. $J$ Infect Dis 1986; 153: 1162-1165.

8. Gouby A, Bourg G, Ramuz M. Previously undescribed 6.6kilobase R plasmid in penicillinase-producing Neisseria gonorrhoeae. Antimicrob Agents Chemother 1986; 29: 1095-1097.

9. Roberts $\mathbf{M}$, Falkow S. Conjugal transfer of $\mathbf{R}$ plasmids in Neisseria gonorrhoeae. Nature 1977; 266: 630-631.

10. PHLS Communicable Disease Report 1987 Sexually transmitted disease in Britain; 1985. No. 45, 3-6.

11. Ison $\mathbf{C} \mathbf{A}$, Gedney $\mathbf{J}$, Harris $\mathbf{J} \mathbf{R} \mathbf{W}$, Easmon $\mathrm{C} \mathbf{S} \mathbf{F}$. Penicillinase producing gonococci: a spent force? Genitourin Med 1986; 62: 302-307.

12. Knapp J S, Tam M R, Nowinski R C, Holmes K K, Sandstrom E G. Serological classification of Neisseria gonorrhoeae with use of monoclonal antibodies to gonococcal outer membrane protein I. J Infect Dis $1984 ; 150: 44-48$

13. Tam M R, Buchanan T M, Sandstrom E G et al. Serological classification of Neisseria gonorrhoeae with monoclonal antibodies. Infect Immun 1982; 36: 1042-1053.

14. Birnboim H C, Doly J. A rapid alkaline extraction procedure for screening recombinant plasmid DNA. Nucleic Acid Res 1979; 7: 1513-1523.

15. Woodford N, Bindayna K M, Easmon C S F, Ison C A. Associations between serotype and susceptibility to antibiotics of Neisseria gonorrhoeae. Genitourin Med $1989 ; 65$ : 86-91.

16. Catlin B W. Nutritional profiles for Neisseria gonorrhoeae, Neisseria meningitidis and Neisseria lactamica in chemically defined media and the use of growth requirements for gonococcal typing. J Infect Dis 1973; 128: 178-194.

17. Copley C G, Egglestone S I. Auxotyping of Neisseria gonorrhoeae isolated in the United Kingdom. $\mathrm{J} \mathrm{Med}$ Microbiol 1983; 16: 295-302.

18. Zenilman J M, Whittington W L, Frazier D, Rice R J, Knapp J S. Penicillinase-producing Neisseria gonorrhoeae in Dade County, Florida: phenotypic characterization of isolates from 1983, 1984 and 1986. Sex Transm Dis 1988; 15: 158-163.

19. Ansink-Schipper M C, Bygdeman S M, van Klingeren B, Sandstrom E G. Serovars, auxotypes and plasmid profiles of PPNG strains with Asian type plasmid isolated in Amsterdam. Genitourin Med 1988; 64: 152155.

20. van Klingeren B, Ansink-Schipper M C, Dessens-Kroon $\mathbf{M}$, Verheuvel $\mathbf{M}$. Relationship between auxotype, plasmid pattern and susceptibility to antibiotics in penicillinase-producing Neisseria gonorrhoeae. J Antimicrob Chemother 1985; 16: 143-147.

21. van Klingeren $B$, van Wijngaarden $L$ J, Dessens-Kroon $M$, van Embden J D A. Penicillinase producing gonococci in the Netherlands in 1981. J Antimicrob Chemother $1983 ; 11: 15-20$.

22. Bygdeman S M. Polyclonal and monoclonal antibodies applied to the epidemiology of gonococcal infection. In: Young $\mathrm{H}$, MacMillan A (eds) Immunological diagnosis of sexually transmitted disease. New York, Marcel Dekker Inc. 1987: 117-165. 